\title{
2000 Influence of different adenosine administrations on the quality of first pass perfusion in cardiac stress MRI Martin Stula* and Michael Liebetrau
}

\author{
Address: Helios Klinik Blankenhain, Blankenhain, Germany
}

* Corresponding author

from I th Annual SCMR Scientific Sessions

Los Angeles, CA, USA. I-3 February 2008

Published: 22 October 2008

Journal of Cardiovascular Magnetic Resonance 2008, I0(Suppl I):A269 doi:10.1 I86/1532-429X-10-SI-A269

This abstract is available from: http://jcmr-online.com/content/I0/SI/A269

(c) 2008 Stula and Liebetrau; licensee BioMed Central Ltd.

\section{Introduction}

Adenosine Stress perfusion is a widely used tool in detecting impaired coronary flow reserve and is one of the standard measurements in cardiac mri to uncover myocardial ischemia under stress conditions. The protocol of this method is long known and was transferred from Nuclear medicine, where it served as myocardial stress equivalent in szintigraphic investigation of the heart: But there are several pitfalls and problems in this method which can decrease the accuracy of adenosine stress testing. Besides artifacts, which have its origins in motion, mr physics and sequence specificities, the main problem is a reduced response of the arterial vessel wall to adenosine and/or stenoses of similar degree in all three coronary trees.

\section{Purpose}

Aim of this study is, to investigate reduced response of the patient to Adenosine and the consequences of this phenomenon on the visually detectable steal effect.

\section{Methods}

In order to detect and document an effect of adenosine in the human there are usually three effects which correlate with adenosine action: (1) Flushing, feeling of heat or dysesthesia in parts of or the whole body; (2) Hyperventilation; (3) Increase of Heart rate for more than $15 \%$ of baseline.

These effects are easy to monitor and to document but it remains unclear whether they correlate in any way with the quantity and the quality of the visually detectable steal effect during infusion of Gadolinium containing contrast agent. We retrospectively observed the three effects of adenosine action with a regular protocol and with a protocol which contained increasing doses of adenosine depending on the change of the three parameters 60,90 seconds and $31 / 2$ minutes after starting the Adenosine infusion.

\section{Results}

640 nondiabetic patients were included in the study (320 regular, $320 \mathrm{VMA})$. In 43 the adenosine stress could not be finished, because of bronchoconstriction ( 3 regular/2 VMA), AV Block II (1 regular/2 VMA) and psychological distress (16 regular/19 VMA). 597 patients were included then in the retrospective analysis. 298 to regular and 299 to variable mode of Adenosine administration (VMA). In the regular group there were 59 patients (negative regular group) with no adequate reaction to adenosine perfusion (No flushing, tachycardia and no hyperventilation) after 3 $1 / 2$ minutes. 2 patients of the negative regular group had a clear positive adenosin stress result. In the VMA group we had 71 patients with no adequate reaction to adenosine after 60 seconds, 20 after 90 seconds and 4 after $31 / 2$ minutes. None of the 4 negative patients had a positive stress test.

\section{Conclusion}

The VMA method gives a better feedback to the investigator, that the adenosine administration had the desired effect, than the regular method. It is as save and convenient for the patient as the regular method. The relevance to the steal phenomenon remains to be investigated but in 5 out of 15 negative patients in the regular group we could 
find significant stenosis in an coronary angiogram, performed afterwards.

Publish with Bio Med Central and every scientist can read your work free of charge

"BioMed Central will be the most significant development for disseminating the results of biomedical research in our lifetime. " Sir Paul Nurse, Cancer Research UK

Your research papers will be:

- available free of charge to the entire biomedical community

- peer reviewed and published immediately upon acceptance

- cited in PubMed and archived on PubMed Central

- yours - you keep the copyright 